\title{
Staphylococcus epidermidis surface protein I (Sesl): a marker of the invasive capacity of $S$. epidermidis?
}

Staphylococcus epidermidis is a commensal that comprises a substantial part of the normal skin flora of humans. The pathogenic potential of this bacterium is, however, low. Nevertheless, when the skin barrier is breached, serious infections can occur, and S. epidermidis has emerged as a major cause of foreign body infections, as well as infections in immunocompromised patients and neonates (Von Eiff et al., 2002; Ziebuhr et al., 2006; McCann et al., 2008; Uçkay et al., 2009).

The virulence factors of $S$. epidermidis have not been fully characterized (Gill et al., 2005; Yao et al., 2005). The main focus has been on the capacity of $S$. epidermidis to adhere to the surfaces of foreign bodies and to matrix proteins of the host, as well as biofilm formation (Von Eiff et al., 2002; Fitzpatrick et al., 2005; Kong et al., 2006; Mack et al., 2007; Otto, 2008).

The surface of the cell wall of S. epidermidis expresses a family of proteins that specifically binds to extracellular host matrix proteins (Desvaux et al., 2006), such as fibrinogen, fibronectin, laminin, elastin and collagen. Some of these proteins display a common C-terminal cell wall sorting signal (CWS) for their correct incorporation into peptidoglycans of the cell wall (Mazmanian et al., 2001; Comfort \& Clubb, 2004; Bowden et al., 2005; Gill et al., 2005; McCrea et al., 2000). This CWS is referred to as the LPXTG (leucine-proline-variable amino acid (X)-threonine-glycine) motif. These cell-wall-associated surface proteins are covalently linked to the cell-membraneassociated transpeptidases, designated sortases, produced by the bacteria. Among $S$. epidermidis, a sortase named surface protein sorting A (SrtA) has been described (Comfort \& Clubb, 2004). SrtA anchors the protein that contains the CWS (Comfort \& Clubb, 2004).

So far, at least 11 different S. epidermidis cell-wall-associated surface proteins with a sortase signal have been identified (Bjertsjö
Rennermalm, 2005; Bowden et al., 2005) including S. epidermidis fibrinogen binding protein (Fbe) (Nilsson et al., 1998), and serine-aspartate repeat protein $\mathrm{F}(\mathrm{SdrF})$ (Bowden et al., 2005). Recently, additional cell-wall-associated surface proteins have been reported, denominated $S$. epidermidis surface (Ses) proteins (Bjertsjö

Rennermalm, 2005; Bowden et al., 2005; Gill et al., 2005). One of these, SesI, consists of 201 amino acids and displays the LPETG motif as a sortase substrate. This protein elicits an immune response with antibody production if the patient is infected with an S. epidermidis isolate expressing SesI during infection (Bowden et al., 2005). These antibodies have also been found to be opsonic, and macrophage phagocytosis is enhanced by antibodies against SesI (Bjertsjö Rennermalm, 2005).

The present work determined the presence of the gene encoding SesI, using a real-time LightCycler PCR system detecting 408 of its 606 bp DNA sequence, among $S$. epidermidis isolates obtained from several patient groups that commonly experienced S. epidermidis infections. Thirty-two $S$. epidermidis isolates obtained during revision operations (multiple tissue biopsies, usually $\geqslant 5$ samples) for prosthetic joint infections (hip, $n=24$; knee, $n=7$; elbow, $n=1$ ) with extraction or exchange were analysed.

Fifty-one S. epidermidis blood isolates collected from patients with haematological malignancies, which had been previously phenotypically and genotypically characterized, were investigated (Persson et al., 2006). The findings of $S$. epidermidis isolates in blood cultures were classified into two groups. Growth of S. epidermidis in both sets of two blood cultures (i.e. four positive cultures), comprising 29 S. epidermidis isolates, was taken to indicate true bacteraemia, while growth in only one of four culture bottles, comprising 22 isolates, was taken to indicate contamination.
In addition, 26 S. epidermidis isolates obtained intraoperatively from cardiac surgery patients included in the LOGIP (local gentamicin for sternal wound infection prophylaxis) trial (Friberg et al., 2005), and previously phenotypically characterized (Olsson et al., 2007), were analysed. Nineteen isolates were from multiple samples (i.e. $>2$ cultures) obtained at reoperation of patients with postoperative sternal wound infection and were regarded as clinically significant isolates. Seven S. epidermidis isolates, interpreted as contaminants, were obtained from cultures from patients who underwent reoperations for indications other than postoperative sternal wound infection, e.g. postoperative tamponade or bleeding, or from a single culture where multiple cultures were negative or displayed the presence of other pathogens. Finally, 13 S. epidermidis isolates from the anterior nares and 11 isolates from the skin of the wrists of 24 healthy individuals without any association with healthcare were also analysed as being representative of commensals.

All isolates were characterized to the species level using the 32 ID API Staph system (bioMérieux). DNA isolation from the reference strain, S. epidermidis RP62A (ATCC 35984), was performed using the MagNA Pure compact system (Roche Molecular Biochemicals) according to the instructions of the manufacturer. Genomic DNA of the clinical isolates was extracted by denaturing one to five colonies suspended in $100 \mu \mathrm{l}$ sterile water at $98{ }^{\circ} \mathrm{C}$ for $15 \mathrm{~min}$ and then centrifuging at $12000 \mathrm{~g}$ for $5 \mathrm{~min}$. The non-diluted supernatant fraction was used as a template for amplification in the real-time PCR.

The PCR for detection of the sesI gene and screening of clinical isolates was performed in a LightCycler 2.0 system (Roche Molecular Biochemicals) using SYBR Green I fluorescence melting curve analysis to detect the specific amplicon. The PCR 
Table 1. Presence of the gene encoding Sesl among $133 \mathrm{~S}$. epidermidis isolates obtained from patients with prosthetic joint infections, from blood culture isolates obtained from patients with haematological malignancies, from isolates obtained during reoperation of cardiac surgery patients, and from commensals obtained from the nares and the skin of the wrists of healthy controls

\begin{tabular}{|lc|}
\hline Sample & No. of sesI-positive isolates (\%) \\
\hline Prosthetic joint infections $(n=32)$ & $21(66 \%)$ \\
Haematological malignancies, bacteraemia $(n=29)$ & $13(45 \%)$ \\
Haematological malignancies, contamination $(n=22)$ & $6(27 \%)$ \\
Cardiac surgery, postoperative, infection $(n=19)$ & $10(53 \%)$ \\
Cardiac surgery, postoperative, contamination $(n=7)$ & $2(29 \%)$ \\
Nares $(n=13)$ & $0(0 \%)$ \\
Skin flora $(n=11)$ & $0(0 \%)$ \\
\hline
\end{tabular}

mixture contained $0.5 \mu \mathrm{M}$ each primer $\left(5^{\prime}\right.$-GCT GAT TAT GTA AAT GAC TCA AAT-3', 5'-AGC TTT TGT TGT TTG AGC TTC-3') (Scandinavian Gene Synthesis), $3 \mathrm{mM} \mathrm{MgCl} 2,1 \times$ LightCycler FastStart DNA master SYBR Green I (Roche Molecular Biochemicals) and PCR-grade $\mathrm{H}_{2} \mathrm{O}$. The PCR programs started with a pre-incubation at $95{ }^{\circ} \mathrm{C}$ for $10 \mathrm{~min}$, followed by 35 cycles of amplification $\left(10 \mathrm{~s}\right.$ denaturation at $95{ }^{\circ} \mathrm{C}$, $10 \mathrm{~s}$ annealing at $57^{\circ} \mathrm{C}$ and $16 \mathrm{~s}$ extension at $72{ }^{\circ} \mathrm{C}$ ); the programs ended with melting curve analysis. In each PCR run, the reference strain was included as a positive control and water was used instead of the DNA template for the negative control.

Initial confirmation of the PCR product was made by means of $2 \%$ agarose gel electrophoresis and DNA sequencing using the ABI BigDye terminator v 1.1 cycle sequencing ready reaction kit (Applied Biosystems) and the ABI Prism 310 genetic analyzer (Applied Biosystems). The sequence of a $389 \mathrm{bp}$ amplification product was found to be $100 \%$ identical with the sesI gene of S. epidermidis strain RP62A (GenBank accession number CP000029.1; base position 16937431693355).

The presence of the sesI gene was more prevalent, although this was not statistically significant, in isolates from all three patient groups than among comparable and representative contaminants (Table 1). However, none of the S. epidermidis isolated from the skin or the nares of healthy individuals representing commensals carried the sesI gene. Comparing S. epidermidis isolates from the three groups of clinically infected patients with the commensals, highly significant differences were found $(P<0.0001$, Fisher's exact test $)$.

This may indicate that the SesI protein is a virulence factor of $S$. epidermidis or at least a marker of invasive capacity. Since healthy people do not regularly carry sesI-positive strains it could be assumed that patients may acquire the sesI-positive strains from the hospital environment after admission and thus rapidly become colonized. This emphasizes the importance of a short preoperative stay in hospital and also appropriate infection control procedures.

Our results regarding the prevalence of the sesI gene among blood culture isolates are in accordance with those of Bowden et al. (2005). However, in that study $29 \%$ of isolates representing normal flora were also found to be sesI-positive, but these $S$. epidermidis isolates were collected from healthy infants and from patients with invasive disease in hospital. In contrast, the prevalence of sesI reported by Bjertsjö Rennermalm (2005) was much higher. However, the number of isolates analysed was limited and the origins of the skin isolates were not specified.

In conclusion, sesI was not found among the normal S. epidermidis flora of healthy individuals without any healthcare association, but was found in approximately $50 \%$ of clinical isolates causing invasive infections. The pathogenic significance of the SesI protein could be further investigated both by using knockout mutants of S. epidermidis in various models and by studying the clinical presentation, course and outcome of infections caused by SesI-expressing isolates compared with sesI-negative $S$. epidermidis. In addition, the dynamics of the antibody response against these cell-wall-associated surface proteins of S. epidermidis should be outlined.

\section{Bo Söderquist, ${ }^{1,2}$ Mira Andersson, ${ }^{1}$ Martin Nilsson, ${ }^{3}$ Åsa Nilsdotter- Augustinsson, ${ }^{4}$ Lennart Persson, ${ }^{2}$ Örjan Friberg ${ }^{5}$ and Susanne Jacobsson ${ }^{1}$}

${ }^{1}$ Department of Clinical Microbiology, Örebro University Hospital, SE-701 85 Örebro, Sweden

${ }^{2}$ Department of Infectious Diseases, Örebro University Hospital, SE-701 85 Örebro, Sweden

${ }^{3}$ Affibody AB, PO Box 20137, SE-161 02 Bromma, Sweden

${ }^{4}$ Department of Infectious Diseases, Linköping University Hospital, SE-581 85 Linköping, Sweden

${ }^{5}$ Department of Cardiothoracic Surgery, Örebro University Hospital, SE-701 85 Örebro, Sweden

\section{Correspondence: Bo Söderquist (bo.soderquist@orebroll.se)}

Bjertsjö Rennermalm, A. (2005). Staphylococcal cell wall associated proteins: characteristics and host interactions, $\mathrm{PhD}$ thesis, Karolinska Institutet, Stockholm, Sweden.

Bowden, M. G., Chen, W., Singvall, J., Xu, Y., Peacock, S. J., Valtulina, V., Speziale, P. \& Höök, M. (2005). Identification and preliminary characterization of cell-wall-anchored proteins of Staphylococcus epidermidis. Microbiology 151, 1453-1464.

Comfort, D. \& Clubb, R. T. (2004). A comparative genome analysis identifies distinct sorting pathways in Gram-positive bacteria. Infect Immun 72, 2710-2722.

Desvaux, M., Dumas, E., Chafsey, I. \& Hébraud, M. (2006). Protein cell surface display in Gram-positive bacteria: from single protein to macromolecular protein structure. FEMS Microbiol Lett 256, 1-15.

Fitzpatrick, F., Humphreys, H. \& O'Gara, J. P. (2005). The genetics of staphylococcal biofilm formation - will a greater understanding of pathogenesis lead to better management of device-related infection? Clin Microbiol Infect 11, 967-973.

Friberg, Ö., Svedjeholm, R., Söderquist, B., Granfeldt, H., Vikerfors, T. \& Källman, J. (2005). Local gentamicin reduces sternal wound infections after cardiac surgery: a randomised controlled trial. Ann Thorac Surg 79, 153-162. 
Gill, S. R., Fouts, D. E., Archer, G. L., Mongodin, E. M., DeBoy, R. T., Ravel, J., Paulsen, I. T., Kolonay, J. F., Brincac, L. \& other authors (2005). Insight on evolution of virulence and resistance from the complete genome analysis of an early methicillin-resistant Staphylococcus aureus strain and a biofilm-producing methicillin-resistant Staphylococcus epidermidis strain. J Bacteriol 187, 2426-2438.

Kong, K. F., Vuong, C. \& Otto, M. (2006). Staphylococcus quorum sensing in biofilm formation and infection. Int J Med Microbiol 296, 133-139.

Mack, D., Davies, P. A. P., Harris, L. G., Rohde, H., Horstkotte, M. A. \& Knobloch, J. K.-M. (2007).

Microbial interactions in Staphylococcus epidermidis biofilms. Anal Bioanal Chem 387, 399-408.

Mazmanian, S. K., Ton-That, H. \& Schneewind, O. (2001). Sortase-catalysed anchoring of surface proteins to the cell wall of Staphylococcus aureus. Mol Microbiol 40, 1049-1057.

McCann, M. T., Gilmore, B. F. \& Gorman, S. P. (2008). Staphylococcus epidermidis device-related infections: pathogenesis and clinical management. J Pharm Pharmacol 60, 1551-1571.

McCrea, K. W., Hartford, O., Davis, S., Eidhin, D. N., Lina, G., Speziale, P., Foster, T. J. \& Höök, M.

(2000). The serine-aspartate repeat (Sdr) protein family in Staphylococcus epidermidis. Microbiology 146, 1535-1546.

Nilsson, M., Frykberg, L., Flock, J.-I., Pei, L., Lindberg, M. \& Guss, B. (1998). A fibrinogenbinding protein of Staphylococcus epidermidis. Infect Immun 66, 2666-2673.

Olsson, E., Friberg, Ö., Venizelos, N., Koskela, A., Källman, J. \& Söderquist, B. (2007). Attachment and accumulation of coagulase-negative staphylococci, isolated from sternal wound infections after cardiac surgery, to sternal fixation stainless steel wires. APMIS 115, 142-151.

Otto, M. (2008). Staphylococcal biofilms. Curr Top Microbiol Immunol 322, 207-228.

Persson, L., Strid, H., Tidefelt, U. \& Söderquist, B. (2006). Phenotypic and genotypic characterization of coagulase-negative staphylococci isolated in blood cultures from patients with hematological malignancies. Eur J Clin Microbiol Infect Dis 25, 299-309.

Uçkay, I., Pittet, D., Vaudaux, P., Sax, H., Lew, D. \& Waldvogel, F. (2009). Foreign body infections due to Staphylococcus epidermidis. Ann Med 41, 109-119.

Von Eiff, C., Peters, G. \& Heilmann, C. (2002). Pathogenesis of infections due to coagulasenegative staphylococci. Lancet Infect Dis 2, 677-685.

Yao, Y., Sturdevant, D. E., Villaruz, A., Xu, L., Gao, Q. \& Otto, M. (2005). Factors characterizing Staphylococcus epidermidis invasiveness determined by comparative genomics. Infect Immun 73, 1856-1860.

Ziebuhr, W., Hennig, S., Eckart, M., Kränzler, H., Batzilla, C. \& Kozitskaya, S. (2006). Nosocomial infections by Staphylococcus epidermidis: how a commensal bacterium turns into a pathogen. Int J Antimicrob Agents 28, S14-S20. 